\title{
First language attrition and reversion among older migrants*
}

\author{
MONIKA S. SCHMID and MEREL KEIJZER
}

\section{Abstract}

Emigration usually requires speakers to become bilingual, and eventually they may even become dominant in their second language. This can lead to a gradual loss of proficiency in the first language, a phenomenon referred to as first language attrition. As migrants become elderly, however, they sometimes report a "reversion" in language dominance, whereby the second language, which they have used in their daily lives for years or decades, recedes and the first language becomes stronger again. There are largely anecdotal cases of communication between such speakers and their children who were not brought up to speak their parents' first language becoming impossible. It is, however, very difficult to separate fact from fiction in such reports.

This article will give an overview of changes in lexical access and fluency in the first language of adult migrants. It will assess simplistic predictions for a linear development of first and second languages against a more complex perspective which takes into account psycholinguistic aspects of activation, inhibition, and cognitive ageing. The predictions made on this basis will be tested on a large-scale quantitative investigation of language proficiency among migrants of German and Dutch descent in the Netherlands and Canada.

\section{Introduction}

Adult speakers who move to a different linguistic environment often experience a change in their first language (L1) proficiency. The language appears to become less easily accessible, and word-finding difficulties, interferences from the second language (L2), and lexical and grammatical "errors" may begin to occur (e.g., Schmid forthcoming). This development 
is referred to as L1 attrition. Over the past few decades, research on this type of linguistic development has gained importance in bilingualism research (for an overview, see Köpke and Schmid 2004). However, the change in bilingual speakers' skills in their first language as they reach old age is an area that has been largely neglected in studies of attrition. This is surprising given the fact that research on language attrition typically investigates speakers who are quite old (the average age reported by most studies is above sixty).

The fact that the majority of the volunteers for attrition studies are in their sixties or older may have psychological reasons. In this phase of life, distant memories often resurface and people find themselves thinking about events and places which had been half-forgotten. Among elderly immigrants we often find a kind of nostalgic preoccupation with the culture of origin. Moreover, they also return to a language which they might have rarely used for decades. This development may be accompanied by a deterioration of the $\mathrm{L} 2$ due to a decrease in use with retirement and as adult children leave the home. Many migrant families adopt the L2 as their home language when their children reach school age, and even couples from the same country of origin often report using the L2 with each other. However, once the children leave home, the same speakers may revert to using the L1 (Clyne 1977). These observations have led to the widely held assumption that linguistic development among elderly migrants will be characterized by two processes:

1. First, language reversion: as immigrants grow older, they tend to use the L1 more than they did in middle age.

2. Second, language attrition: as immigrants grow older, they tend to forget vocabulary and lose grammatical rules that they used in middle age (de Bot and Clyne 1989: 168).

It is, however, very difficult to separate fact from fiction in reports of L1 reversion or L2 attrition among migrant populations, since there does not appear to be a single empirical study of attrition that specifically tests the impact of age on healthy elderly bilinguals' language skills. References are almost invariably vague and inconclusive, e.g.: "It is common knowledge these days [...] that ageing is often accompanied by language reversion" (Haines 1999) or "research [...] clearly shows that language reversion in later life is very common" (Fronditha Care Inc. 2005). Some of the observed cases may be linked to pathological factors such as early dementia, which can selectively affect a bilingual's languages (Fabbro 1999). In other cases, the conclusion that language reversion has occurred is not based on actual observations of linguistic behavior (and compari- 
sons to earlier behavior) but on self-reports or reports by relatives and friends (de Bot and Clyne 1989; de Bot and Lintsen 1986).

Communication across age ranges — between "old" and "young" people - has been the focus of much attention in recent years. It has been shown that such interactional situations are often fraught with difficulty and frustrations. Younger people tend to experience their older communication partners as "under-accommodative," "inattentive," "non-listening," and generally feel that interactions with older communication partners are less satisfying than those with same-age partners. Older people, on the other hand, often feel patronized and may experience their younger interlocutors as "over-accommodating" in that they use overly simple language (Williams and Harwood 2004: 121-122), a phenomenon referred to as "elderspeak" (de Bot and Makoni 2005: 1621). It is therefore unclear to what degree the problems reported by healthy elderly migrants and those in close contact with them are more frequent or more serious than those experienced in monolingual crossgenerational interaction. Situations where communication with a close family member comes to be perceived as problematic can be threatening to both interlocutors. Such problems may therefore be attributed to the convenient and ubiquitous myth of language reversion, since this relieves the participants of responsibility: it is "just" a language problem.

Language reversion in old age appears to be the one context of language attrition that is surrounded by the most persistent myths. The change in linguistic development among elderly migrants is therefore potentially the most confusing and disturbing to both the speaker and those closest to him or her. However, there is to date no empirical research which might be able to shed more light on this issue.

\section{The development of bilingual proficiency across the lifespan of adult migrants}

Migration is a highly disruptive life event which almost invariably has large-scale ramifications through all areas of social and professional life. Usually, it also means that the individuals will have to become bilingual, and will have to function in a language with which they did not grow up, and in which they may not feel entirely comfortable in a wide range of settings. The process of becoming an L2 speaker has been the focus of a great deal of linguistic research, in particular in the attempt to assess how L2 learning is different from L1 learning. Such research is characterized by a long-standing bias toward investigations of later-learned or weaker languages (Cook 2003). It is assumed that findings on whether such languages are represented or used differently from what we can observe in 
native speakers will allow us to better understand the nature of language learning or language use, and eventually provide us with fundamental insights into the human mind (e.g., Hawkins 2001). There is good reason for this assumption: findings from learners who have acquired a second language after childhood or puberty are often different from what can be observed in monolinguals (DeKeyser 2000). Most foreign language learners never reach fully native speaker levels of proficiency and often show more variability in the application of some rules or features than monolinguals (e.g., Sorace 2005).

More recently it has been recognized that becoming bilingual also impacts on the first language (Cook 2003; Schmid forthcoming). It has been amply demonstrated that a bilingual individual is not two monolingual individuals in the same mind/person (e.g., Dijkstra and van Heuven 2002; Grosjean 2001). Once a speaker has acquired two (or more) languages, all of them will be active and, to some degree, accessed during language processing, and a return to a completely monolingual mode is impossible (Grosjean 2001). Consequently, bilingual processing can always be assumed to incur a higher cognitive load, and to be more strongly affected by constraints on working memory than monolingual processing. This can lead to a reduction in fluency, a slowdown in lexical access, and interferences on the lexical, phonological, and grammatical levels in both languages.

In this context, a neurolinguistic perspective on the management of linguistic knowledge in the bilingual mind is relevant. A model for this has been provided in the Activation Threshold Hypothesis (ATH). According to this model, ease of access to items (words, rules, phonemes) in either language system of a bilingual depends on frequency (how often the item has been called upon) and time (how long ago it was last activated) (Paradis 1993, 2004, 2009). Disuse of a language system most immediately affects accessibility of lexical items, but will eventually also impact on grammatical knowledge (Köpke 2007; Paradis 2004, 2007). In other words, the less often a bilingual uses one of her languages, the more difficult she will find it to retrieve the correct lexical and grammatical information from memory under the time pressure of normal discourse. Conversely, a language which is spoken frequently will come to feel more and more comfortable and natural to the speaker.

On the basis of this model, it might be predicted that migrants will become gradually and steadily "better" in the L2 and "worse" in the L1 with increased length of residence and continuous exposure to L2, while L1 input is mainly absent. That view, however, may be overly simplistic, since the activation threshold crucially depends not only on frequency/ recency of activation, but also on the inhibition of non-relevant informa- 
tion (Green 1998). Every time we attempt to recall a certain item of knowledge from memory, a number of similar memory traces will compete for selection, and it is the most highly active item (the one with the lowest activation threshold) which will win out. This means that in order for the correct item to be selected, all competitors have to be inhibited, and this mechanism of inhibition will raise their activation threshold, so that for them to be activated again the next time will require more cognitive effort (Paradis 2004).

In the bilingual mind, inhibition is a crucial process. Where two language systems are represented in the same mind, there is a large number of items with a high degree of similarity; e.g., words in both languages which mean roughly the same and are differentiated only by their phonological form. Anyone who has ever tried to speak a foreign language which they have not used for any length of time will be familiar with the initial interference from their stronger language(s). The effort needed to suppress or inhibit these languages is often very great at first, and then subsides rapidly, as the momentarily undesired language becomes less accessible (because inhibition has raised its activation threshold) and the target language becomes more accessible (because activation has lowered its activation threshold).

On the basis of the twin processes of activation and inhibition, a somewhat more detailed prediction can therefore be made for the initial stages of bilingual development in a migrational setting: due to the sudden and highly intensive exposure upon arrival in the new country, there will be a rapid increase in proficiency, fluency, and activation in the L2. At the same time, the speaker has to invest a great deal of effort in order to inhibit her highly active L1. This will lead to a relatively sudden rise in the activation threshold of that language, so that the speaker may experience what she will perceive as a fast (and often startling) "language loss." The perception of migrants that they are "losing" their language during the first decade of emigration has often been reported (Beganovic 2006; Hutz 2004). With increasing proficiency and fluency in the L2, and increasing practice in inhibiting one language system when switching between the two, both the "learning" and the "forgetting" curves may eventually stabilize: as ultimate attainment (or fossilization) in the L2 is reached, attrition effects in the $\mathrm{L} 1$ will also slow down.

\section{Cognitive ageing, inhibition processes, and bilingualism}

The activation threshold model can provide some insight into the processes of language change in elderly bilingual speakers on the basis of 
recent findings from research on cognitive ageing. It has been shown that what is often and frustratingly experienced as "memory loss" among the elderly is not, in fact, the outcome of information represented in memory deteriorating or becoming unavailable, but of processes of inhibition becoming less effective (e.g., Burke 1997; Burke and Osborne 2007; Burke and Shafto 2008; Radvansky et al. 2005). The forgetfulness which elderly people often appear to experience is therefore not necessarily due to the fact that information has been "forgotten" or has become inaccessible. It has merely become more difficult to suppress other information which may be similar or associated to the memory that the person is trying to retrieve, and therefore access to the target is blocked. Intriguingly, this apparently general cognitive ageing phenomenon appears to be delayed in healthy elderly speakers who became bilingual at an early age, as has been shown by Bialystok et al. (2004).

It thus appears that a bilingual's practice at inhibiting irrelevant information can help slow down cognitive ageing processes which make the process of inhibition less effective. However, as and when the elderly bilingual begins to encounter this ageing phenomenon, it can also be assumed to impact on the management of both linguistic systems, resulting in not only more language interference, but also an increase in (involuntary) code switching, as well as impaired fluency, as memory retrieval and lexical access become affected. These are all phenomena that have been observed often among elderly bilingual populations (e.g., de Bot and Clyne 1989; Goral 2004).

\section{Summary and research questions}

Social and cognitive ageing can impact on communicative behavior and on performance on experimental and linguistic tasks. These processes will be experienced both by monolinguals and by bilinguals, but they may vary with respect to the extent of their impact and the age at which they occur. In order to assess the assumptions of L1 reversion for elderly bilingual speakers, it is therefore necessary to compare performance of such populations on a variety of tasks against age-matched monolingual populations, and to investigate differences between the two samples at a range of different ages.

For migrants over the age of sixty, the separation of the two linguistic systems may become compromised as inhibition processes become overall less efficient. This means that linguistic access may be slowed down and code-switching phenomena may increase. As speakers pass retirement age, on the other hand, accessibility of the L1 may be facilitated again 
due to an increase in use of and exposure to this language and a reduction in the contexts in which the L2 is spoken.

We can therefore predict that migrants over the age of sixty will score lower than younger speakers on tasks that measure the efficiency of lexical access. A similar development should be evident in monolingual speakers of the same age group, but the ageing effect should be less pronounced here, since these speakers only have to inhibit competing items from one linguistic system. The differences between monolingual and bilingual speakers will become less pronounced beyond retirement age.

This study will focus on lexical access and fluency phenomena, as these have been shown to be most prone to impairment in both cognitive ageing and attrition (see above). In particular, it will address the following research questions:

RQ1 L1 attrition effects: Are migrant populations outperformed by monolingual reference populations on linguistic tasks measuring lexical access?

RQ1a Verbal fluency: Are migrant populations outperformed by monolingual reference populations on verbal fluency tasks?

RQ1b Lexical diversity: Do migrant populations have lower indices of lexical diversity in free speech than monolingual reference populations?

RQ1c Disfluency phenomena: Do migrant populations exhibit a higher frequency of disfluency phenomena (hesitations, repetitions) in free speech than monolingual reference populations?

RQ2 Age effects: Is there an age effect with respect to the attrition phenomena investigated under RQ1?

RQ2a Cognitive ageing effect: Are speakers above the age of sixty outperformed by younger speakers?

RQ2b Bilingualism effect: Is there a difference in this cognitive ageing effect between migrant and monolingual reference populations?

RQ2b Language reversion effect: Do L1 attrition effects become smaller or disappear after retirement age?

\section{The study}

\subsection{Participants}

This study is based on an analysis of spoken data from 249 speakers. The participants fall into five categories: 
- GECA $(n=53)$ : a group of native speakers of German living in Canada. This group consisted of 19 men $(35.8 \%)$ and 34 women $(64.2 \%)$ with a mean age of 63.27 years (SD 11.02). They had lived in Canada for a minimum of 15 years (mean 37.07 years, SD 12.49) and had been at least 17 years old when they emigrated (mean 26.19, SD 7.20). All participants in this group lived in the Greater Vancouver area in British Columbia (none had ever lived in the French-speaking area of Canada).

- GENL $(n=53)$ : a group of native speakers of German living in the Netherlands. This group consisted of 18 men $(34.0 \%)$ and 35 women $(66.0 \%)$ with a mean age of 63.28 years (SD 9.48). They had lived in the Netherlands for a minimum of 15 years (mean 34.52, SD 11.27) and had been at least 17 years old when they emigrated (mean 28.76, SD 7.19). All participants in this group lived in the Randstad, the densely populated and highly urbanized area between Amsterdam and Rotterdam (none had ever lived in areas where Frisian is spoken).

- GECG $(n=53)$ : a control group of native speakers of German living in Germany. This group consisted of 18 men $(34.0 \%)$ and 35 women $(66.0 \%)$ with a mean age of 60.88 years (SD 11.60). None of the participants in this group had ever lived outside Germany, nor did any of them use a language other than German on a regular basis.

- NLCA $(n=45)$ : a group of native speakers of Dutch living in Canada. This group consisted of 21 men $(46.5 \%)$ and 24 women $(53.5 \%)$ with a mean age of 66.44 years (SD 7.38). They had lived in Canada for a minimum of 15 years (mean 44.42, SD 9.11) and had been at least 17 years old when they emigrated (mean 22.02, SD 5.99). All participants in this group lived in Ontario (none had ever lived in the French-speaking area of Canada).

- NLCG $(n=45)$ : a control group of native speakers of Dutch living in the Netherlands. This group consisted of 21 men (46.5\%) and 24 women $(53.5 \%)$ with a mean age of 66.24 years (SD 7.95). None of the participants in this group had ever lived outside of the Netherlands for an extended period of time, nor did any of them use a language other than Dutch on a regular basis.

5.1.1. Covariates. While all efforts were made to ensure that sociolinguistic factors which might impact on performance, such as gender, were controlled across the groups, the limited availability of participants made a completely even distribution impossible. We encountered similar problems with respect to educational levels. On the basis of the educational systems of Germany and the Netherlands, the following four levels were established: Level 1 comprised those participants who had com- 
Table 1. Distribution of educational levels across groups

\begin{tabular}{lrrrrrr}
\hline & GECA & GENL & GECG & NLCA & NLCG & Total \\
\hline Level 1: Pre-vocational training & \multicolumn{1}{c}{13} & 9 & 13 & 3 & 1 & 39 \\
Level 2: Vocational training & 22 & 21 & 23 & 20 & 15 & 101 \\
Level 3: University entry level & 5 & 6 & 6 & 8 & 11 & 33 \\
Level 4: University degree & 13 & 17 & 11 & 14 & 18 & 57 \\
\hline
\end{tabular}

pleted the minimum schooling requirement of pre-vocational training; for the German participants this refers to the Volksschule or Hauptschule, for the Dutch participants to primary education (basisschool); Level 2 comprises the German Realschule or Mittlere Reife and the Dutch VMBO, as well as vocational training; Level 3 were those people who completed the schooling requirement for university entrance (German [Fach-]Abitur and Dutch VWO); and Level 4 are those people who received a degree from a university or polytechnic. As can be seen from Table 1, there are some differences across groups with respect to these educational levels.

Since sex and education could not be controlled across groups, these factors will be included in the analyses as covariates in order to ensure that possible findings are not distorted.

5.1.2. Age levels. Since the age effect, predicted above and addressed in RQ2, is non-linear, it cannot be captured by statistical procedures such as correlations or regressions. It was therefore deemed necessary to divide the sample into age groups which would allow analyses of variance per group. Ideally, of course, these groups should have covered age ranges of similar size; however, the distribution of participants across the

Table 2. Distribution and range of age groups

\begin{tabular}{|c|c|c|c|c|c|c|c|c|c|c|}
\hline \multirow[t]{2}{*}{ Age range } & \multicolumn{3}{|c|}{ All } & \multicolumn{3}{|c|}{ Attriters } & \multicolumn{3}{|c|}{ Controls } & \multirow{2}{*}{$\begin{array}{l}\text { Length of } \\
\text { residency } \\
\text { (in years) }\end{array}$} \\
\hline & Age $n$ & mean & SD & Age $n$ & mean & SD & Age $n$ & mean & SD & \\
\hline$<57$ & 53 & 48.60 & 5.59 & 30 & 49.00 & 6.06 & 23 & 48.09 & 5.01 & 23.00 \\
\hline $57-64$ & 50 & 61.40 & 2.32 & 30 & 61.63 & 2.22 & 20 & 61.05 & 2.48 & 30.50 \\
\hline $65-67$ & 47 & 65.85 & 0.75 & 27 & 65.81 & 0.74 & 20 & 65.90 & 0.79 & 32.74 \\
\hline $68-71$ & 52 & 69.27 & 1.03 & 37 & 69.22 & 0.98 & 15 & 69.40 & 1.18 & 32.84 \\
\hline 72 & 47 & 76.24 & 4.34 & 27 & 76.36 & 4.30 & 20 & 76.10 & 4.49 & 41.04 \\
\hline
\end{tabular}


age band and within the groups made such an analysis impossible because the resulting groups would have been too unequal. The populations were therefore divided into five age groups of approximately equal size (see Table 2). This division also allowed us to focus on the periods before and just after the average retirement age of 65 . Note that for the attriting population a higher age almost invariably implies a longer period of residence (the correlation of these two factors across our population was highly significant: $\left.r^{2}=0.26, P<0.001\right)$.

\subsection{Method}

The experiments on which the present study is based were part of a larger investigation on language attrition among Dutch and German migrants conducted in 2004 by the authors of this article (the first author collected the data from the L1 German speakers while the second collected the L1 Dutch data). The experiment used the test battery devised by Schmid (2005). As the purpose of this article is to investigate the development of lexical access and fluency among migrants, the following experiments will be included in the analysis:

1. Semantic verbal fluency (VF). Following Goodglass and Kaplan (1983), in this task participants were asked to name as many items in a specific lexical category as they could within the space of 60 seconds. Two tasks were used: one with the stimulus "animals" and the other with "fruits and vegetables." The final VF measure was an averaged measure of the scores of the two individual tasks. ${ }^{1} \mathrm{~A}$ high score on the VF task reflects high proficiency.

2. Free speech. Free speech samples were elicited by means of the Charlie Chaplin film-retelling task as used by Perdue (1993). These retellings were typically around 10-15 minutes long and measured 750 words on average. The following variables were established on the basis of the transcripts of these data:

- Lexical richness or diversity (D). D is a measure of type-token ratios based on a random sampling of stretches of 50 words; i.e., it is not sensitive to variation in text length (see McKee et al. 2000). A high score reflects low type-token ratios; i.e., greater lexical diversity.

- Disfluency. For each speech sample, the number of filled pauses (FP) and repetitions (REP) was counted and subsequently recalculated per 1,000 words (for more details on this analysis, see Schmid and Fägersten forthcoming). 
- Code switches (CS). For each speech sample, all items which unambiguously belonged to the L2 were counted (pronunciation was taken into account here; where in doubt, the item was counted as L1). The number of code switches was subsequently recalculated per 1,000 words. Since there was no code switching in the monolingual control groups (as was to be expected), no group comparisons between attriters and controls could be made for this variable.

\section{Results}

In order to determine whether there were any effects of language attrition among the migrant groups, independent $t$-tests were conducted for all of the dependent variables described above. ${ }^{2}$ For all variables with the exception of filled pauses, the differences were significant at the $P<0.01$ level (see Table 3), indicating that the attriters were outperformed by the controls on all other dependent variables measured here.

In answer to research questions RQ1a-RQ1c above, we can therefore say that lexical access does appear affected for the attriters: they have lower scores on the fluency task and on lexical diversity, and they are more disfluent than the controls as indicated by a tendency to repeat lexical material (REP), although there is no overuse of filled pauses (FP).

Having established that there are indeed attrition effects among the migrant group for all of these variables, we then investigated the impact of age on performance. In order to do this, group means per condition and age group were first calculated for each of the dependent variables (see Table 4). (For full descriptive statistics, including standard deviations, see the appendix.)

In answer to RQ2a, there does appear to be an overall cognitive ageing effect here, in that on the whole, the older groups tend to be outperformed by the younger ones. Where the effects of bilingualism and language reversion (RQ2b and RQ2c) are concerned, there are two

Table 3. Comparison of dependent variables: attriters versus controls (independent t-tests)

\begin{tabular}{|c|c|c|c|c|c|c|c|}
\hline & \multicolumn{2}{|c|}{ Attriters } & \multicolumn{2}{|c|}{ Controls } & \multirow[t]{2}{*}{$t$-test } & & \multirow{2}{*}{$\begin{array}{l}\text { Effect size } \\
\text { (r) }\end{array}$} \\
\hline & mean & $\mathrm{SD}$ & mean & $\mathrm{SD}$ & & & \\
\hline VF & 19.80 & 4.51 & 23.68 & 4.85 & $t(244)=6.392$ & $P<0.001$ & 0.38 \\
\hline $\mathrm{D}$ & 62.99 & 16.36 & 69.36 & 16.22 & $t(243)=2.998$ & $P=0.003$ & 0.19 \\
\hline FP & 48.70 & 34.98 & 46.49 & 32.18 & $t(243)=0.501$ & $P=0.617$ & 0.03 \\
\hline REP & 12.92 & 10.67 & 6.70 & 5.33 & $t(243)=-5.344$ & $P<0.001$ & 0.32 \\
\hline
\end{tabular}


Table 4. Mean results per condition and age group on dependent variables

\begin{tabular}{lllllrl}
\hline & Age range & VF & D & FP & REP & CS \\
\hline ATTRITERS & $<57$ & 22.33 & 66.88 & 36.52 & 10.21 & 4.24 \\
& $57-64$ & 20.02 & 68.55 & 50.63 & 12.92 & 8.01 \\
& $65-67$ & 19.91 & 63.22 & 48.87 & 9.20 & 5.08 \\
& $68-71$ & 17.95 & 56.89 & 63.02 & 17.49 & 11.52 \\
CONTROLS & $72+$ & 19.17 & 60.66 & 40.15 & 13.48 & 10.10 \\
& $<57$ & 25.89 & 73.64 & 43.84 & 6.41 & - \\
& $57-64$ & 24.55 & 72.23 & 53.30 & 6.04 & - \\
& $65-67$ & 23.60 & 68.46 & 53.56 & 6.12 & - \\
& $68-71$ & 21.61 & 65.92 & 38.36 & 6.82 & - \\
& $72+$ & 21.76 & 65.05 & 41.76 & 8.17 & - \\
\hline
\end{tabular}

Table 5. ANCOVAs for age groups (education and sex as covariates), all speakers

\begin{tabular}{llrlllll}
\hline $\begin{array}{l}\text { Dependent } \\
\text { variable }\end{array}$ & $F$ & Sig. & Partial $\eta^{2}$ & \multicolumn{4}{c}{ Difference from group $<57$ (significance) } \\
\cline { 5 - 8 } & & & & $57-64$ & $65-67$ & $68-71$ & $72+$ \\
\hline VF & 5.969 & $<0.001$ & 0.128 & 0.053 & 0.058 & $<0.001$ & 0.001 \\
D & 3.080 & 0.006 & 0.073 & 0.771 & 0.392 & 0.004 & 0.050 \\
FP & 5.549 & $<0.001$ & 0.125 & 0.093 & 0.178 & 0.032 & 0.886 \\
REP & 2.942 & 0.009 & 0.070 & 0.417 & 0.718 & 0.003 & 0.150 \\
\hline
\end{tabular}

interesting observations to be made on the basis of these results: first, the attriters in the age range of 68-71 are outperformed by all other groups on every one of the dependent variables under observation. Second, while this is also the age group where the contrast between attriters and controls is largest, this difference virtually disappears among the 72-yearold+ group: for this group, the differences between attriters and controls are the smallest on all dependent variables (except repetitions, where the 65-67-year-olds and the youngest group are more similar to the controls). This might indeed indicate a somewhat beneficial effect of bilingualism for cognitive ageing in our oldest age ranges, and/or a recovery effect for this group due to language reversion.

In order to test the observed differences between age groups statistically, analyses of covariance (ANCOVAs) were performed for the dependent variables. In these analyses, gender and educational level of the speakers were included as covariates (since these variables were not distributed evenly across groups, as discussed above). Simple contrasts were chosen, with the youngest group of speakers as the reference group. For all dependent variables, the overall effect of age group was significant (see 
Table 6. ANCOVAs for age groups (education and sex as covariates), attriters only

\begin{tabular}{llclllll}
\hline $\begin{array}{l}\text { Dependent } \\
\text { Variable }\end{array}$ & $F$ & Sig. & Partial $\eta^{2}$ & \multicolumn{4}{c}{ Difference from group $<57$ (significance) } \\
\cline { 5 - 8 } & & & & $57-64$ & $65-67$ & $68-71$ & $72+$ \\
\hline VF & 3.189 & 0.006 & 0.121 & 0.078 & 0.146 & 0.003 & 0.049 \\
D & 2.202 & 0.046 & 0.087 & 0.559 & 0.695 & 0.062 & 0.305 \\
FP & 4.679 & $<0.001$ & 0.168 & 0.157 & 0.162 & 0.009 & 0.721 \\
REP & 2.474 & 0.026 & 0.096 & 0.362 & 0.805 & 0.014 & 0.256 \\
CS & 1.925 & 0.0081 & 0.077 & 0.284 & 0.987 & 0.018 & 0.122 \\
\hline
\end{tabular}

Table 7. ANCOVAs for age groups (education and sex as covariates), controls only

\begin{tabular}{llllllll}
\hline $\begin{array}{l}\text { Dependent } \\
\text { variable }\end{array}$ & $F$ & Sig. & Partial $\eta^{2}$ & \multicolumn{3}{c}{ Difference from group $<57$ (significance) } \\
\cline { 5 - 8 } & & & & $57-64$ & $65-67$ & $68-71$ & $72+$ \\
\hline VF & 3.338 & 0.005 & 0.187 & 0.396 & 0.386 & 0.019 & 0.009 \\
D & 1.014 & 0.422 & 0.065 & 0.841 & 0.554 & 0.116 & 0.118 \\
FP & 2.304 & 0.041 & 0.137 & 0.242 & 0.563 & 0.710 & 0.796 \\
REP & 0.783 & 0.585 & 0.051 & 0.891 & 0.907 & 0.757 & 0.249 \\
\hline
\end{tabular}

Table 5). The contrasts revealed that the 68-71-year-olds were different from the youngest speakers on all dependent variables. The 72-year-old+ group was outperformed by the youngest speakers on the verbal fluency (VF) task, and there also was a marginally significant difference from the reference category for this group in lexical richness/diversity (D).

These findings confirm the observation made on the basis of the distribution of group averages above: the only age group which has systematically lower scores than the youngest group is not the group with the oldest participants, but the group that is between 68 and 71 years old. This group is outperformed on all tasks by the speakers who are younger than 57 years. In order to assess whether the impact of age might have been different for the two conditions, the analyses were repeated for the attriting group only (Table 6) and for the controls only (Table 7). In the former analysis, code switches (CS) were included as a dependent variable.

As is evident from this analysis, the peak of the attrition effect in the 68-71 age group, which was apparent in Table 4 above, is indeed statistically significant for all variables except lexical diversity (D), where it approaches significance. The oldest group of attriters, on the other hand, does not perform differently from the youngest group, nor are there 
differences for any of the other age groups, except on verbal fluency (VF). Among the controls, the only age effect to be observed is a lower score on the verbal fluency task for the two oldest age groups.

\section{Discussion}

The first result from the analysis presented in this article is that there was attrition among the sampled migrant population with respect to lexical access, as indicated by the lower scores achieved by these speakers in verbal fluency (VF) tasks as well as in lexical diversity (D) and fluency in free speech in comparison with predominantly monolingual reference groups. This finding corroborates the results from other investigations conducted on data from these speakers (Keijzer 2007; de Leeuw et al. forthcoming; Schmid 2007; Schmid and Dusseldorp forthcoming), which established that the migrants did indeed suffer $\mathrm{L} 1$ attrition across a range of tasks and linguistic skills.

We then proceeded to investigate how different these attrition effects were in the various stages of life represented across our population samples. In order to assess this, we adopted a novel approach. Based on the theoretical background presented above, we expected an age effect, but we did not expect it to be linear for the experimental condition: we predicted that it would not be the oldest migrant speakers whose performance would show the largest signs of attrition, but speakers who were around or just past retirement age, and hypothesized that there might be some degree of recovery of L1 skills beyond this age - possibly due to a change in environment. Furthermore, we predicted that the oldest bilingual speakers might perform better than the others in comparison with their age-matched reference population - possibly because they are reaping the benefits of long-term routine bilingualism, as was proposed by Bialystok et al. (2004).

Our findings corroborated these assumptions: in the control population we found a more or less linear (though not significant) decrease of scores across the five age groups. For the experimental population, the lowest scores on all dependent variables were achieved by the population aged between 68 and 71 at the time of data collection. The older migrant speakers outperformed this group: they did not differ in their performance from the youngest speakers, and were also the migrant group whose results were closest to that of the control population of their own age in other words, although these were generally the speakers with the longest residency period, they had the smallest attrition effects. This result may well indicate that there is in fact such a phenomenon as L1 rever- 
sion. At the same time, however, another factor could have played a role, namely that the oldest migrants had survived until this stage. Research on cognitive change across the lifespan has found that the "oldest old" (i.e., people of around 75 or older) did not show strong effects of cognitive ageing, presumably because of their strong cognitive skills, which in turn may have been caused by a healthy physique (Rabbitt et al. 2008).

What these findings unambiguously indicate is that future analyses of the impact of age on processes of language attrition and reversion, and possibly on overall bilingual proficiency, should not be confined to investigations of linear effects, as these may mask the true developments. It is also noteworthy how narrow the age segment is for which a peak in attrition effects was found. Smaller-scale investigations, which have to confine themselves to larger age intervals in order to maintain group sizes allowing statistical comparisons would not have detected this effect.

While the present investigation is not a longitudinal one, and therefore only allows very tentative conclusions with respect to developments, these findings do indicate that a certain degree of language reversion may have taken place after retirement among the oldest speakers in our sample. On the basis of the data analyzed here, it is impossible to say whether such a development may have been caused by a change in linguistic habits or environment, by the beneficial effects of long-term bilingualism, or the fact that the oldest speakers can be classified as "survivors" on cognitive ageing processes - or by an interaction of these factors. Future analyses of these data, taking into account self-reports and autobiographical narratives, may provide deeper insight.

University of Groningen

Utrecht University

Correspondence address: m.s.schmid@rug.nl 


\begin{tabular}{|c|c|c|c|c|c|c|c|c|c|c|c|}
\hline & & $\begin{array}{l}\mathrm{VF} \\
\text { mean }\end{array}$ & SD & $\begin{array}{l}\mathrm{D} \\
\text { mean }\end{array}$ & SD & $\begin{array}{l}\text { FP } \\
\text { mean }\end{array}$ & SD & $\begin{array}{l}\text { REP } \\
\text { mean }\end{array}$ & SD & $\begin{array}{l}\mathrm{CS} \\
\text { mean }\end{array}$ & SD \\
\hline \multirow[t]{5}{*}{ ALL } & $<57$ & 23.88 & 5.05 & 69.87 & 17.73 & 39.76 & 31.60 & 8.52 & 7.48 & - & - \\
\hline & $57-64$ & 21.78 & 5.06 & 70.05 & 19.25 & 51.72 & 32.61 & 10.11 & 8.53 & - & - \\
\hline & $65-67$ & 21.48 & 4.14 & 65.45 & 16.50 & 50.87 & 37.48 & 7.89 & 6.82 & - & - \\
\hline & $68-71$ & 18.95 & 4.59 & 59.55 & 13.28 & 55.77 & 38.40 & 14.35 & 13.42 & - & - \\
\hline & 72 & 20.24 & 4.82 & 62.57 & 13.01 & 40.85 & 25.39 & 11.17 & 7.97 & - & - \\
\hline \multirow[t]{5}{*}{ ATT } & $<57$ & 22.33 & 4.34 & 66.88 & 14.65 & 36.52 & 21.32 & 10.21 & 8.62 & 4.24 & 5.11 \\
\hline & $57-64$ & 20.02 & 4.41 & 68.55 & 21.43 & 50.63 & 34.65 & 12.92 & 9.10 & 8.01 & 10.67 \\
\hline & $65-67$ & 19.91 & 3.94 & 63.22 & 15.92 & 48.87 & 42.64 & 9.20 & 7.79 & 5.08 & 6.56 \\
\hline & $68-71$ & 17.95 & 4.33 & 56.89 & 13.52 & 63.02 & 39.55 & 17.49 & 14.60 & 11.52 & 17.05 \\
\hline & 72 & 19.17 & 4.51 & 60.66 & 13.28 & 40.15 & 25.73 & 13.48 & 8.57 & 10.10 & 9.97 \\
\hline \multirow[t]{5}{*}{$\mathrm{CON}$} & $<57$ & 25.89 & 5.28 & 73.64 & 20.71 & 43.84 & 41.30 & 6.41 & 5.16 & - & - \\
\hline & $57-64$ & 24.55 & 4.87 & 72.23 & 15.83 & 53.30 & 30.22 & 6.04 & 5.67 & - & - \\
\hline & $65-67$ & 23.60 & 3.47 & 68.46 & 17.18 & 53.56 & 29.98 & 6.12 & 4.90 & - & - \\
\hline & $68-71$ & 21.61 & 4.31 & 65.92 & 10.55 & 38.36 & 29.96 & 6.82 & 4.91 & - & _- \\
\hline & 72 & 21.76 & 4.94 & 65.05 & 12.55 & 41.76 & 25.57 & 8.17 & 6.07 & - & - \\
\hline
\end{tabular}




\section{Notes}

* The investigation of L1 German speakers included in this analysis was supported by NWO grant 275-70-005.

1. For seven of the 249 informants, only one of the two VF tasks was available due to equipment failure. In these cases, the single score was used.

2. No group comparisons could be run for code switches, as the predominantly monolingual controls did not use these.

\section{References}

Beganovic, Jasminka. 2006. First language attrition and syntactic subjects: A study of Serbian, Croatian, and Bosnian intermediate and advanced speakers in Dutch. Edinburgh: University of Edinburgh MA thesis. http://www.era.lib.ed.ac.uk/bitstream/1842/2045/ 1/Jasminka+Beganovic.pdf (accessed 26 May 2009).

Bialystok, Ellen, Fergus I. M. Craik, Raymond Klein \& Mythili Viswanathan. 2004. Bilingualism, aging, and cognitive control: Evidence from the Simon task. Psychology and Aging 19(2). 290-303.

Burke, Deborah. 1997. Language, aging, and inhibitory deficits: Evaluation of a theory. Journal of Gerontology 52B(6). 254-264.

Burke, Deborah \& Gabrielle Osborne. 2007. Aging and inhibition deficits: Where are the effects? In David S. Gorfein \& Colin M. MacLeod (eds.), On the place of inhibitory processes in cognition, 63-183. Washington, DC: American Psychological Association Press.

Burke, Deborah \& Meredith A. Shafto. 2008. Language and aging. In Fergus I. M. Craik \& Timothy A. Salthouse (eds.), The handbook of aging and cognition, 373-443. New York: Psychology Press.

Clyne, Michael. 1977. Bilingualism in the elderly. Talanya 4. 45-65.

Cook, Vivian. 2003. Introduction: The changing L1 in the L2 user's mind. In Vivian Cook (ed.), Effects of the second language on the first, 1-18. Clevedon: Multilingual Matters.

de Bot, Kees \& Michael Clyne. 1989. Language reversion revisited. Studies in Second Language Acquisition 11. 167-177.

de Bot, Kees \& Toke Lintsen. 1986. Foreign-language proficiency in the elderly. In Bert Weltens, Kees de Bot \& Theo van Els (eds.), Language attrition in progress, 131-141. Dordrecht: Foris.

de Bot, Kees \& Sinfree Makoni. 2005. Language and aging in multilingual contexts. Clevedon: Multilingual Matters.

DeKeyser, Robert. 2000. The robustness of critical period effects in second language acquisition. Studies in Second Language Acquisition 22. 499-533.

de Leeuw, Esther, Monika S. Schmid \& Ineke Mennen. forthcoming. Perception of foreign accent in native speech. Bilingualism: Language and Cognition 13(1).

Dijkstra, Ton \& Walter J. B. van Heuven. 2002. The architecture of the bilingual word recognition system: From identification to decision. Bilingualism: Language and Cognition 5(3). 175-197.

Fabbro, Franco. 1999. The neurolinguistics of bilingualism: An introduction. Hove: Psychology Press.

Fronditha Care Inc. 2005. Senate community affairs references committee inquiry into aged care. http://wopared.aph.gov.au/Senate/committee/clac_ctte/completed_inquiries/200407/aged_care04/submissions/sub224.pdf (accessed 26 May 2009). 
Goodglass, Harold \& Edith Kaplan. 1983. The assessment of aphasia and related disorders. Philadelphia: Lea and Febiger.

Goral, Mira. 2004. First language decline in healthy aging: Implications for attrition in bilingualism. Journal of Neurolinguistics 17(1). 31-52.

Green, David. 1998. Mental control of the bilingual lexico-semantic system. Bilingualism: Language and Cognition 1(2). 67-81.

Grosjean, François. 2001. The bilingual's language modes. In Janet Nicol (ed.), One mind, two languages: Bilingual language processing, 1-22. Oxford: Blackwell.

Haines, Timothy. 1999. STTARS \& refugee resettlement in South Australia. MS, Adelaide. http://international.metropolis.net/events/washington/Haines.doc (accessed 26 May 2009).

Hawkins, Roger. 2001. Second language syntax. Oxford: Blackwell.

Hutz, Matthias. 2004. Is there a natural process of decay? A longitudinal study of language attrition. In Monika S. Schmid, Barbara Köpke, Merel Keijzer \& Lina Weilemar (eds.), First language attrition: Interdisciplinary perspectives on methodological issues, 189-206. Amsterdam: John Benjamins.

Keijzer, Merel. 2007. Last in first out? An investigation of the regression hypothesis in Dutch emigrants in Anglophone Canada. Utrecht: LOT.

Köpke, Barbara. 2007. Language attrition at the crossroads of brain, mind, and society. In Barbara Köpke, Monika S. Schmid, Merel Keijzer \& Susan Dostert (eds.), Language attrition: Theoretical perspectives, 9-37. Amsterdam: John Benjamins.

Köpke, Barbara \& Monika S. Schmid. 2004. First language attrition: The next phase. In Monika S. Schmid, Barbara Köpke, Merel Keijzer \& Lina Weilemar (eds.), First language attrition: Interdisciplinary perspectives on methodological issues, 1-43. Amsterdam: John Benjamins.

McKee, Gerard, David Malvern \& Brian Richards. 2000. Measuring vocabulary diversity using dedicated software. Literary and Linguistic Computing 15(3). 323-337.

Paradis, Michel. 1993. Linguistic, psycholinguistic, and neurolinguistic aspects of interference in bilingual speakers: The activation threshold hypothesis. International Journal of Psycholinguistics 9(2). 133-145.

Paradis, Michel 2004. A neurolinguistic theory of bilingualism. Amsterdam: John Benjamins.

Paradis, Michel. 2007. L1 attrition features predicted by a neurolinguistic theory of bilingualism. In Barbara Köpke, Monika S. Schmid, Merel Keijzer \& Susan Dostert (eds.), Language attrition: Theoretical perspectives, 121-134. Amsterdam: John Benjamins.

Paradis, Michel. 2009. Declarative and procedural determinants of second languages. Amsterdam: John Benjamins.

Perdue, Clive. 1993. Adult language acquisition: Cross-linguistic perspectives. Volume 1: Field methods. Cambridge: Cambridge University Press.

Rabbitt, Patrick, Mary Lunn \& Danny Wong. 2008. Death, dropout, and longitudinal measurements of cognitive change in old age. Journal of Gerontology 63B(5). 271-278.

Radvansky, Gabriel A., Rose T. Zacks \& Lynn Hasher. 2005. Age and inhibition: The retrieval of situation models. Journal of Gerontology 60B(5). 276-278.

Schmid, Monika S. 2005. The language attrition test battery: A research manual. Amsterdam: Vrije Universiteit Amsterdam manuscript.

Schmid, Monika S. 2007. The role of L1 use for L1 attrition. In Barbara Köpke, Monika S. Schmid, Merel Keijzer \& Susan Dostert (eds.), Language attrition: Theoretical perspectives, 135-153. Amsterdam: John Benjamins.

Schmid, Monika S. Forthcoming. Languages at play. Bilingualism: Language and Cognition 13(1).

Schmid, Monika S. \& Elise Dusseldorp. Forthcoming. Quantitative analyses in a multivariate study of language attrition. Second Language Research 26(1). 
Schmid, Monika S. \& Kristy Beers Fägersten. Forthcoming. The development of disfluency markers in L1 attrition. Language Learning 60(4).

Sorace, Antonella. 2005. Syntactic optionality at interfaces. In Leonie Cornips \& Karen Corrigan (eds.), Syntax and variation: Reconciling the biological and the social, 46-111. Amsterdam: John Benjamins.

Williams, Angie \& Jake Harwood. 2004. An intergroup perspective on intergenerational relationships in the family. In Jon F. Nussbaum \& Justine Coupland (eds.), Handbook of communication and aging research, 115-138. Mahwah, NJ: Erlbaum. 